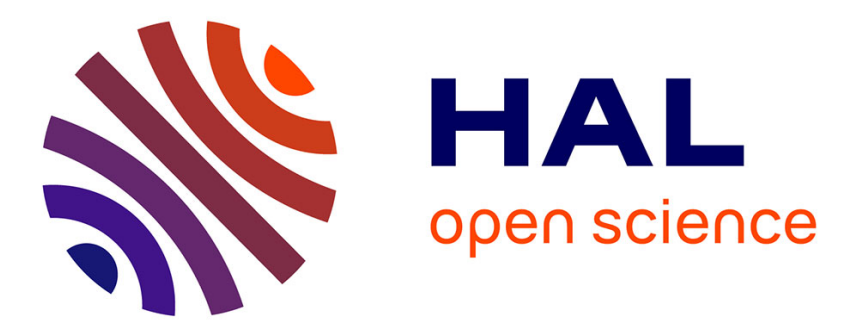

\title{
A developmental study of the self-prioritization effect in children between 6 and 10 years of age
}

Hélène Maire, Renaud Brochard, Daniel Zagar

\section{To cite this version:}

Hélène Maire, Renaud Brochard, Daniel Zagar. A developmental study of the self-prioritization effect in children between 6 and 10 years of age. Child Development, 2020, 91 (3), pp.694-704. 10.1111/cdev.13352 . hal-02385577

\section{HAL Id: hal-02385577 \\ https://hal.univ-lorraine.fr/hal-02385577}

Submitted on 11 May 2020

HAL is a multi-disciplinary open access archive for the deposit and dissemination of scientific research documents, whether they are published or not. The documents may come from teaching and research institutions in France or abroad, or from public or private research centers.
L'archive ouverte pluridisciplinaire HAL, est destinée au dépôt et à la diffusion de documents scientifiques de niveau recherche, publiés ou non, émanant des établissements d'enseignement et de recherche français ou étrangers, des laboratoires publics ou privés.

\section{다)(1) $(5$}

Distributed under a Creative Commons Attribution - NonCommerciall 4.0 International 


\section{A developmental study of the self-prioritization effect in children between 6 and 10 years of age}

Hélène Maire ${ }^{1}$, Renaud Brochard ${ }^{2}$ and Daniel Zagar ${ }^{1}$

${ }^{1}$ University of Lorraine, Nancy, France.

${ }^{2}$ University Bourgogne Franche-Comté, Dijon, France.

Correspondence concerning this article should be addressed to:

Hélène MAIRE

Université de Lorraine

23 boulevard Albert Ier

54015 NANCY Cedex

France

Email: helene.maire@univ-lorraine.fr

Telephone: +33680408800

\section{Pour citer cet article :}

Maire, H., Brochard, R., \& Zagar, D. (2020). A developmental study of the self-prioritization effect in children between 6 and 10 years of age. Child Development. doi: $10.1111 /$ cdev. 13352 
Abstract: Self-biases are well described in adults but remain poorly understood in children. Here, we investigated in 6-10 year old children $(\mathrm{N}=132)$ the self-prioritization effect (SPE), a self-bias which reflects, in adults, the perceptual advantage for stimuli arbitrarily associated with the self as compared to those associated with other persons. We designed a child-friendly adaptation of a paradigm originally introduced in adults by Sui, He and Humphreys (2012) in order to test whether the SPE also occurs in children and if so, to determine its evolution with age. A robust SPE was obtained from the age of 6 , and this effect was similar-sized in our four age-groups. These findings are discussed with reference to the development of the self during childhood.

Key words: Self; self-prioritization; self-reference effect 
The self provides coherence and continuity to the ebb and flow of subjective experience (James, 1890; Neisser, 1988) and guides attention, cognition and affect. To carry out this important ecological function in everyday life, self-related stimuli are spontaneously favored or prioritized, resulting in some affective or cognitive self-biases. Affective selfbiases refer to a preference for self-related stimuli ( "mere ownership effect", "endowment effect”, "mere belongingness to self effect”; e.g., Beggan, 1992; Knetsch, 1989; Nuttin, 1985) while cognitive self-biases refer to enhanced processing for self-related information. Nowadays, these latter biases are mainly experimentally investigated through the paradigm of the "self-reference effect" (SRE) which refers to a self-advantage in memory, i.e. better encoding and better subsequent recall or recognition for information associated with self-cues (e.g., Cunningham \& Turk, 2017; Rogers, Kuiper, \& Kirker, 1977; Symons \& Johnson, 1997; Turk, Bos, Collard, Gillespie-Smith, Conway, \& Cunningham, 2013; van den Bos, Cunningham, Conway, \& Turk, 2010).

A large body of research has replicated the SRE among children and investigated its developmental evolution during childhood (Cunningham, Brebner, Quinn, \& Turk, 2014; Cunningham, Vergunst, Macrae, Turk, 2013; Halpin Puff, Mason, \& Marston, 1984; Pullyblank, Bisanz, Scott, \& Champion, 1985; Ray, Shelton, Hollon, Michel, Frankel, Gross, \& Gabrieli, 2009; Ross, Anderson, \& Campbell, 2011; Sui \& Zhu, 2005; see also Cunningham, Scott, Hutchison, Ross, \& Martin, 2018, and Turk, Gillespie-Smith, Krigolson, Havard, Conway, \& Cunningham, 2015, for educational applications). Many of these research works used the same adult evaluative encoding paradigm: personality traits or physical characteristics are explicitly evaluated with reference to the self (e.g., "Are you shy?"), to an other person (e.g., "Is your mum calm?”), or in terms of semantic features (e.g., "Is tidy a nice word?”) or physical features (e.g. "Does small have an 's' sound?”). Then a trait recall or recognition task is used to assess whether encoding the stimuli with reference to the self 
elicits a memory advantage. An SRE was obtained in 7-year-old children, but not in 6-yearolds (Halpin et al., 1984). However, this classic evaluative encoding paradigm was possibly too difficult and not discriminating enough for young children since the items were abstract trait-descriptive adjectives. In order to make the task easier for younger children, some researchers have used pictorial evaluative encoding tasks, in which a concrete object was evaluated with reference to the self or to other represented through cartoon figures depicted with their own or another child's face. The figures were shown pointing at an object (Ross et al., 2011, Experiment 2; Sui \& Zhu, 2005), using it (Ross et al., Experiments 1, 3 and 4), owning it (“ownership paradigm": Cunningham et al., 2013; Ross et al., 2011, Experiment 7; Ross, Hutchison, \& Cunningham, 2019), or simply liking it (Cunningham et al., 2014, Experiments 1 and 2). With such age-appropriate tasks, these studies demonstrated an SRE in children as young as five-year-olds (Sui \& Zhu, 2005), four-year-olds (Cunningham et al., 2013, 2014) and even three-year-olds (Ross et al., 2011), in subsequent recognition test ("is the object new or old?") and source memory test ("was the old object presented with self or with other?") (Cunningham et al., 2014, Experiments 2 and 3; Ross et al., 2019).

In classic evaluative encoding tasks involving adjectives, the SRE was typically regarded as resulting from high-level processes and requiring the explicit activation of the self-concept. In this view, it is because the self is a well-developed and often-used construct, involving an increasing depth of processing (Craik \& Lockhart, 1972) and promoting both elaboration and organization of encoded information, that self-related memory traces are more accessible and subsequently more easily retrieved than non-self-related memory traces (e.g., Andersen, Glassman, \& Gold, 1998; Keenan, Golding, \& Brown, 1992; Klein, Loftus, \& Schell, 1994). Yet, the use of pictorial evaluative encoding tasks involving self-face (e.g. Cunningham et al., 2014; Ross et al., 2011, 2019; Sui \& Zhu, 2005) suggest that attention bias may also contribute to the SRE, with the mere presence of children's own face, because of its high familiarity, eliciting an implicit activation of the self. In this line, other research led to 
the alternate explanation that the SRE is likely to rather result from low-level, automatic processes, which are responses to self-cues (Cunningham et al., 2014, p.820). Indeed, the self elicited physiological arousal (Bargh, 1982) and self-biases might be underpinned by an automatic (i.e., unconscious, unintentional and uncontrolled) capture of attention by selfrelated stimuli (Alexopoulos, Muller, Ric, \& Marendaz, 2012). According to this view, the SRE would not require effortful activation of the self-concept, but only the mere presence of a self-cue, which is enough to make encoding more efficient (Turk, Cunningham, \& Macrae, 2008, p.1043). Indeed, these authors did obtain an SRE in adults in an "incidental encoding" condition, i.e. without any explicit evaluative processing since participants were simply instructed to indicate whether a trait adjective appeared above a referent cue or not.

Subsequently, Cunningham and colleagues (2014, Experiment 3) investigated whether an SRE could also be elicited in 4 to 6 year-old children in the absence of an explicit activation of the self-concept. To that purpose, they used an ingenious task involving an incidental, non-evaluative encoding, i.e. entailing only a minimal (but not conscious) selfrelated information processing. Their participants were presented with their own or another child's face in the middle of the screen, and were simply asked to report on which side of the screen (right or left) the object had been presented. In such minimal form of self-related information processing conditions, an SRE has been obtained (see also Ross et al., 2019, in 3 to 6 year-old children). These results led the authors to conclude that the children's SRE did not require high-level and effortful processes, but might also be driven by automatic attentional response. This conclusion is also supported by a series of experiments carried out by Cunningham and colleagues in 4 to 6 year-old children. Taken together, their results showed that the SRE were age-invariant across 4 to 6 years in both recognition and source memory tests, and with both evaluative and incidental tasks (Cunningham et al., 2014), as well as uncorrelated with some high-level cognitive abilities such as working memory 
(Cunningham et al., 2014, Experiment 2), Theory of Mind and verbal abilities (Cunningham et al., 2013).

However, the Cunningham and colleagues' incidental encoding paradigm uses the child's own face, which is both a highly familiar and overlearned stimulus that is a priori associated to the self, preventing from distinguishing between the effect of familiarity and the effect of the self on memory. Moreover, one could notice that the incidental encoding paradigm provides an "off-line" measure of the self-advantage, since it is quantified by subsequent memory scores assessing long after the perception of the stimulus. Yet, if the SRE is well driven by low-level responses to self-cues (Cunningham et al., 2014; Turk et al., 2008), the automatic attentional capture should occur from the early stages of processing (i.e., when the stimulus is perceived, during the encoding phase), and a self-bias should yet be observed at this step. Actually such an off-line measure might also be responsive to high-level subsequent influences between the encoding and the recognition or source memory phases and being likely to contaminate the assessment of a putative "pure" low-level self-advantage. If so, the obtained SRE could actually be a mixed effect which may not only result from the automatic attentional capture elicited by the self, but also from additional self-advantages intertwining both low- and high- level processes.

Following Cunningham and colleagues in their quest for a deeper understanding of the processes underlying the SRE in children, especially through the mere automatic responses to the self, our study aims to capture them by means of a self-bias described as perceptual in the adult literature : the "self-prioritization effect" (SPE). In this paradigm introduced by Sui, He and Humphreys (2012), different geometric shapes are temporarily and arbitrarily associated with self-related (e.g., "you") and non-self-related (e.g., "friend", "stranger", "mother") labels. In a subsequent matching task, this association leads to an SPE, i.e. faster and more accurate verifications of self-related matched shape-label pairings than non-self-related ones (e.g., Fuentes, Sui, Estevez, \& Humphreys, 2016; Schäfer, Wentura, \& Frings, 2015, 2017; 
Stein, Siebold, \& van Zoest, 2016; Sui, Sun, Peng, \& Humphreys, 2014; Sui, Yankouskaya, \& Humphreys, 2015; Wang, Humphreys, \& Sui, 2016). SPE has also been extended from visual perception to action (Frings \& Wentura, 2014) as well as to other sensory modalities such as audition and touch (Schäfer, Wesslein, Spence, Wentura, \& Frings, 2016) and has been shown to involve similar but distinct processes from reward (Sui \& Humphreys, 2015b; Sui, Ohrling, \& Humphreys, 2016). The SPE in adults, which is the "substantial advantage for matching shapes to a self label, relative to when the shapes were linked to familiar others and/or to an unfamiliar person/a neutral label" (Sui et al., 2012, p.1115), has been reliably identified as a perceptual self-bias. Indeed, the visual degradation of shapes, known to alter early stages of visual processing, has been shown to interact with the SPE (Sui et al., 2012, Experiment 4; see also subsequent investigations using Signal Detection Theory: Moradi, Sui, Hewstone, \& Humphreys, 2015; Sui \& Humphreys, 2015a). Moreover, in a global-local task, both selfrelevant and perceptually salient shapes were found to increase interference as compared with non-self-relevant or non-salient shapes (Sui, Liu, Mevorach, \& Humphreys, 2015). Furthermore, self-associated stimuli do have functional and neural properties similar to perceptual saliency (Humphreys \& Sui, 2015; see also Liu \& Sui, 2016; Sun, Fuentes, Humphreys, \& Sui, 2016). Since the SPE has been strongly established as a perceptual selfadvantage, it should be driven by mere low-level processes, and the matching task should not (or very minimally) be sensitive to the influences of high-level processes. Another important feature of this paradigm is that it uses temporary and arbitrary "self" or "non-self" shape-label pairings rather than highly familiar and overlearned "self" or "non-self" stimuli (participants' own face or strangers' face), making it possible to capture the "pure" effect of the self rather than the effect of the self to which a simple familiarity effect is added.

In the current study, we propose a child-friendly variation on the standard matching task developed by Sui and colleagues (2012), specifically designed to evidence a putative perceptual, automatic self-advantage in 6-10 year-old children, and if so, whether such an 
effect would remain stable or not with age. The present variation uses children's drawings (drawing of self vs. drawing of others) because they avoid familiarity effect elicited by faces (self- vs. other- face) and are more concrete and more engaging than written labels ("you" vs. "friend", "stranger"). We hypothesize that since the SPE (i.e., faster and accurate responses for matched self-related than non-self-related trials; Sui et al., 2012) reflects automatic responses to self-cues, its size should not depend on the age of the children.

\section{Method}

\section{Participants}

The sample comprised 132 children aged 6-10 years, including 30 "first grade" $\left(M_{\text {age }}=\right.$ 6.37 years, age range $=6.33$ to 7.16 years, $S D_{\text {age }}=0.49,12$ girls $), 40$ "third grade" $\left(M_{\text {age }}=8.4\right.$ years, age range $=8.2$ to 9.24 years, $S D_{\text {age }}=0.56,17$ girls $), 26$ "fourth grade" $\left(M_{\text {age }}=9.31\right.$ years, age range $=9.25$ to 10.2 years, $S D_{\text {age }}=0.47,16$ girls $)$, and 36 "fifth grade" $\left(M_{\text {age }}=\right.$ 10.36 years, age range $=10.25$ to 11.33 years, $S D_{\text {age }}=0.49,19$ girls). To reinforce the readability of the text, these four groups will later be designed as "6 years", "8 years", "9 years" and "10 years" groups (corresponding to Grade 1, Grade 3, Grade 4 and Grade 5 groups, respectively). All participants spoke French as a first language and were pupils at primary urban schools from mixed socio-economic backgrounds in Lorraine (France). The children were tested after obtaining the oral consent as well as the written consent of their parents, the school teachers, the school directors and the District Supervisor. Recruitment was carried out with the school teachers.

\section{Materials}

In our child variation of Sui and colleagues' matching task (2012), the written labels ("you", "friend", "stranger") were replaced by drawings representing three characters: themselves ("you"), their best friend ("friend") and an unknown child ("stranger" or "other"). 
These characters were produced by the children themselves on blank sheets of paper during the first meeting with the experimenter (i.e., the "drawing of the characters" session, see Procedure section below). They were then scanned, reframed and integrated into a personalized version of the E-prime program. Similarly, abstract geometric shapes (square, circle, triangle) were replaced by pictures of three imaginary vacation spots (a trailer, an igloo, a teepee, see Figure 1). These vacation spots were selected because they are wellknown to children since they are frequent in youth literature. Meanwhile, they represent imaginary vacation since spending vacation under a teepee, or an igloo, or in a horse-drawn trailer remain quite uncommon in France. Thus, it was unlikely that these vacation forms could have been previously experienced by our young participants and could convey selfknowledge. During the second meeting with the experimenter (i.e., the "matching task" session, see Procedure section below), each vacation spot $\left(3.8^{\circ} \times 3.8^{\circ}\right)$ was presented alongside one the three characters above a white fixation cross $\left(1.1^{\circ} \times 1.1^{\circ}\right)$ at the center of the screen. The pairings of the three vacation spots with the self, friend, or other conditions was counterbalanced across participants. Each character (self, friend, other) $\left(3.6^{\circ} \times 1.6^{\circ}\right)$ was displayed below the fixation cross while the vacation spot was displayed above. The distance between the center of the screen and the fixation cross was $3.5^{\circ}$. All stimuli were shown on a gray background. Participants were asked to judge whether the pairings of the vacation spot and the character matched (e.g., Does YOUR FRIEND go on holiday in the teepee? Do YOU go on holiday in the igloo? Does THE OTHER CHILD go on holiday in the trailer?). The experiment was run on a PC using E-prime software (Version 2, Science Plus Group, Groningen, The Netherlands). The stimuli were displayed on a 20 -in. monitor $(1,600 \mathrm{x}$ 900 pixels at $60 \mathrm{~Hz}$ ). 

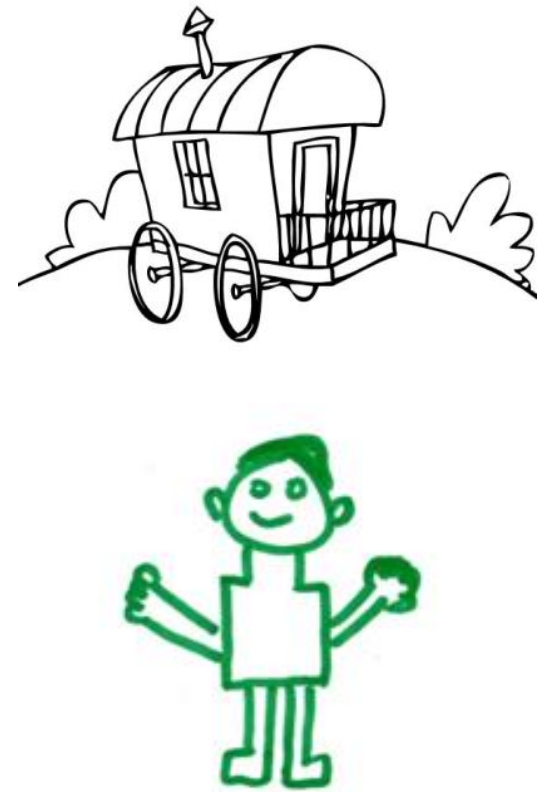
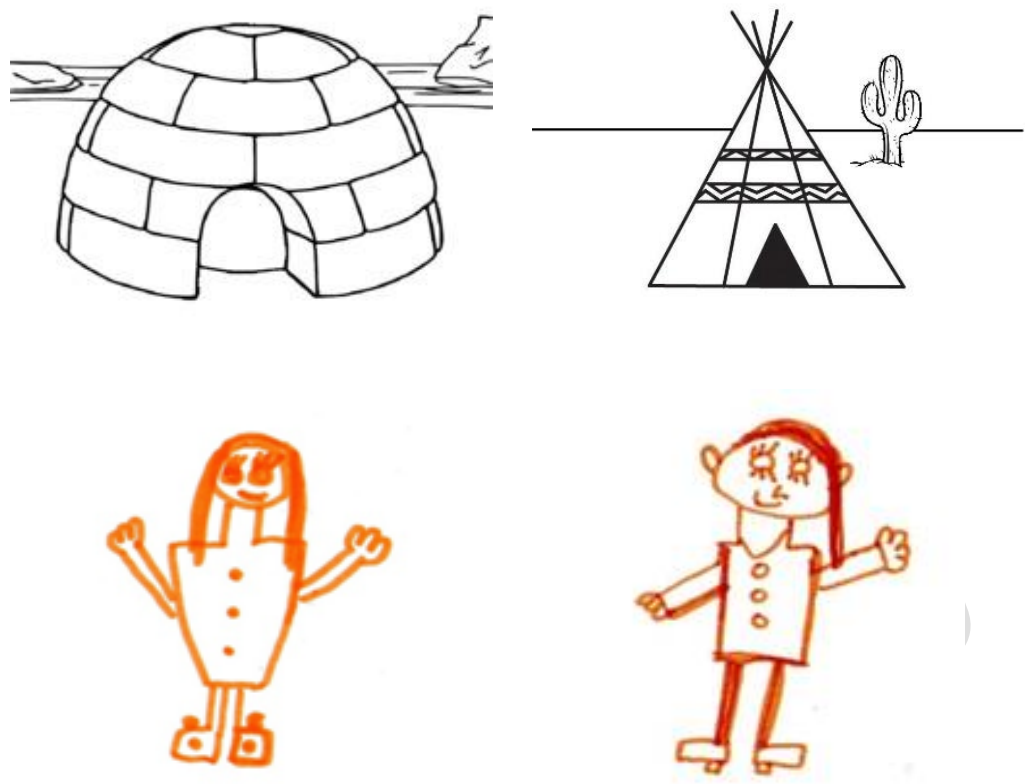

Figure 1: Examples of three personalized pairings of one character (self, friend, other) with one vacation spot (trailer, igloo, teepee). The three characters had previously been drawn by each child.

\section{Procedure}

In our child-friendly variation of the Sui and colleagues' paradigm, the experimenter met each child on two different sessions, separated by one week.

Drawings of the characters. During the first meeting, children were gathered in same-sex groups of three or four in a quiet room away from the classroom. Each participant was given three blank paper sheets with a $10 \times 14 \mathrm{~cm}$ frame inside. They were asked to draw three characters which would be used for playing a computerized game when the experimenter would return one week later. They were instructed to draw themselves, then their best friend of the opposite sex (a girl for boys, a boy for girls), and an unknown sameage child of the opposite sex, which was presented as a cousin of the experimenter in order to make him/her more concrete for children. Each child had three pencils of different colors (green, purple, brown) and was asked to pick a different color of their choice for each character. Once each child had completed his/her three drawings, they were thanked and 
walked back to the classroom. No time restriction was given, however all sessions lasted about fifteen minutes. Drawings were then scanned, reframed and integrated into a version of the E-prime program, thus personalized for each participant.

Matching task. One week later, children were taken individually away from the classroom and tested by the experimenter in a quiet room. They told that they would play a computerized game with the characters he/she had drawn one week earlier: "In the game, each character goes on holiday in a vacation spot." Three random pairings between a vacation spot (trailer, teepee, igloo) and a character (self, friend, other) were displayed on screen. The experimenter systematically checked that the participant remembered who each drawing referred to. Then the purpose of the game was explained. The participant was instructed that he/she had to learn specific pairings: "On the screen you will see one character and one vacation spot. You will have to answer if the character is in his/her proper vacation spot. We will practice together before we start". A learning phase (with the characters and the vacation spots displayed in paper format) and a practice phase (on the computer screen) were proposed before the experimental phase. The learning phase consisted of six consecutive oral questions with drawings of the characters and vacation spots in paper format as support: the first half of the questions were about the characters displayed on paper ( "Who goes on holiday in the trailer?", "Who goes on holiday in the teepee?", "Who goes on holiday in the igloo?", in a random order), then the second half of the questions were about the vacation spots displayed on paper ("Where does your friend go on holiday?", "Where do you go on holiday?", "Where does the unknown child go on holiday?", in a random order). Participants gave their response orally by pointing to it on the sheet. This learning phase was repeated if participants made more than two errors. If not, the practice phase was proposed directly on the computer screen. Participants sat approximately $50 \mathrm{~cm}$ from the screen. They were instructed to press one of two buttons on the keyboard to indicate as accurately and quickly as possible 
whether the presented character-vacation spot pairing was correct or not. Each trial started with the presentation of a central fixation cross for $500 \mathrm{~ms}$. The next frame showed a blank for a duration of $100 \mathrm{~ms}$. Subsequently, a pairing of a character and a vacation spot was presented for 1,000 ms. The temporal response window showed a blank for a maximal duration of 6,000 ms. Each response was followed by an emoticon used as feedback for 1,000 ms. The emoticon for an incorrect response was a neutral cartoon face, the emoticon for a correct response was a smiling cartoon face and the emoticon for a correct and quick response (i.e., shorter than 1,000 ms) was a smiling cartoon face with thumbs up. After the instructions had been given and the emoticons had been explained, the practice phase began (12 trials). After this practice phase, the experimental blocks started. Each participant was presented with 10 blocks of 12 trials. In both the learning and experimental blocks, half of the trials corresponded to matched pairings and the other half to non-matched pairings. Each character and each vacation spot occurred equally often in a random order. Thus, each block contained two trials in each condition (self-matched, self-non-matched, friend-matched, friend-nonmatched, other-matched, and other-non-matched). Participants had been told that they could take a break between each block if they wished, but none of them asked for it.

In summary, our experiment had a mixed design with two within-subjects factors: Character (self, friend, other) and Matching condition (matched trials, non-matched trials), and one between-subjects factor: Mean age $(6,8,9,10)$.

\section{Results}

Mean proportions of correct responses, mean reaction times and $\mathrm{d}$ prime values are shown in Table 1. 
Table 1: RTs in ms (and Accuracy) and d' as a Function of Character (Self, Friend, Other) for Matched and Non-Matched Trials in the "6 years", "8 years", "9 years" and "10 years" mean age groups (Grade 1, Grade 3, Grade 4 and Grade 5 groups, respectively).

\begin{tabular}{|c|c|c|c|c|c|c|c|c|c|}
\hline & \multicolumn{6}{|c|}{ RT and Accuracy } & \multicolumn{3}{|c|}{ d' } \\
\hline & \multicolumn{3}{|c|}{ Matched trials } & \multicolumn{3}{|c|}{ Non-matched trials } & \multirow[b]{2}{*}{ Self } & \multirow[b]{2}{*}{ Friend } & \multirow[b]{2}{*}{ Other } \\
\hline & Self & Friend & Other & Self & Friend & Other & & & \\
\hline \multirow{2}{*}{6 years } & $879(77 \%)$ & $978(66 \%)$ & $996(74 \%)$ & $1072(64 \%)$ & $1053(64 \%)$ & $1047(65 \%)$ & 1.333 & 0.896 & 1.245 \\
\hline & {$[240(20 \%)]$} & [304 (21\%)] & {$[283(18 \%)]$} & [295 (20\%)] & [293 (20\%)] & {$[289(21 \%)]$} & [1.049] & [0.967] & [1.107] \\
\hline \multirow{2}{*}{8 years } & $792(76 \%)$ & $936(61 \%)$ & $921(63 \%)$ & $935(60 \%)$ & $1012(63 \%)$ & $988(64 \%)$ & 1.195 & 0.841 & 0.922 \\
\hline & {$[132(15 \%)]$} & [193 (20\%)] & [213(19\%)] & {$[143(18 \%)]$} & {$[196(18 \%)]$} & {$[198(16 \%)]$} & {$[1]$} & [1.037] & [0.859] \\
\hline \multirow{2}{*}{9 years } & $758(82 \%)$ & $921(73 \%)$ & $872(76 \%)$ & $928(70 \%)$ & $1003(78 \%)$ & $979(72 \%)$ & 1.714 & 1.595 & 1.496 \\
\hline & [105 (20\%)] & {$[112(17 \%)]$} & {$[113(20 \%)]$} & {$[94(17 \%)]$} & {$[133(16 \%)]$} & {$[114(16 \%)]$} & [1.077] & [0.995] & [0.831] \\
\hline \multirow{2}{*}{10 years } & $724(85 \%)$ & $925(74 \%)$ & $900(81 \%)$ & $891(76 \%)$ & $962(76 \%)$ & $965(74 \%)$ & 1.855 & 1.545 & 1.698 \\
\hline & {$[88(19 \%)]$} & {$[127(17 \%)]$} & {$[157(17 \%)]$} & {$[112(13 \%)]$} & {$[115(17 \%)]$} & {$[144(17 \%)]$} & {$[0.945]$} & [0.924] & [0.854] \\
\hline
\end{tabular}

Note. $\mathrm{RT}=$ reaction time for correct responses. Accuracy $=$ percentage of correct responses. Standard deviations are indicated in square brackets.

\section{Reaction Times}

A 3 (character: self, friend, other) x 2 (matching condition: matched trials, nonmatched trials) x 4 (mean age: $6,8,9,10$ ) repeated-measures analysis of variance (ANOVA) was conducted on RTs (values below $300 \mathrm{~ms}$ or above 2,000 ms, i.e. $3.40 \%$ of the correct responses were discarded). This analysis revealed a main effect of matching condition ( $F(1$, 128) $=335.39, p<.001, \eta_{\mathrm{p}}{ }^{2}=0.72$ ) with shorter RTs for matched trials than for non-matched trials $\left(M_{\text {matched }}=883 \mathrm{~ms}, M_{\text {non-matched }}=984 \mathrm{~ms}\right)$, a trend main effect of age $(F(3,128)=2.50$, $\left.p<.10, \eta_{\mathrm{p}}^{2}=0.02\right)$ with RTs becoming shorter with age $\left(M_{6}\right.$ years $=1004 \mathrm{~ms}, M_{8}$ years $=931$ $\left.\mathrm{ms}, M_{9 \text { years }}=910 \mathrm{~ms}, M_{10 \text { years }}=894 \mathrm{~ms}\right)$, and a main effect of character $(F(2,256)=92.60$, $\left.p<.001, \eta_{\mathrm{p}}^{2}=0.21\right)$ with shorter RTs for "self" $\left(M_{\text {self }}=870 \mathrm{~ms}\right)$ trials than for "other" $\left(M_{\text {other }}=\right.$ $958 \mathrm{~ms})$ and "friend" $\left(M_{\text {friend }}=973 \mathrm{~ms}\right)$ trials. Post-hoc Tukey comparisons revealed that RTs for "self" trials were significantly shorter than RTs for "other" $(p<.001)$ and for "friend" $(p<$ .001) trials, while RTs for "other" and "friend" trials were not significantly different $(p>.05)$. There was a significant Character $\mathrm{x}$ Matching condition interaction $(F(2,256)=31.00, p$ $<.001, \eta_{\mathrm{p}}{ }^{2}=0.10$ ), with a larger effect of character for matched trials than for non-matched trials, which, according to Sui and colleagues (2012), is the signature of the SPE. A significant Character $\mathrm{x}$ Age interaction was also found $\left(F(6,256)=3.94, p<.001, \eta_{\mathrm{p}}{ }^{2}=0.01\right)$. The Character $\mathrm{x}$ Matching condition $\mathrm{x}$ Age interaction was not significant $(p>.05)$ indicating that 
the SPE on RTs is age-invariant between 6- and 10-year-old (see Figure 2). The analyses were then conducted for the matched and the non-matched trials separately. The data showed a significant effect of Character for the matched trials $\left(F(2,256)=99.82, p<.001, \eta_{\mathrm{p}}{ }^{2}=0.22\right)$, reflecting a "self"-association advantage $\left(M_{\text {self }}=787 \mathrm{~ms}\right)$ over "friend"- and "other"associations $\left(M_{\text {friend }}=940 \mathrm{~ms} ; M_{\text {other }}=923 \mathrm{~ms}\right.$ ), i.e. the SPE. For the non-matched trials, a significant but lesser effect of Character was also obtained $\left(F(2,256)=14.89, p<.001, \eta_{\mathrm{p}}{ }^{2}=\right.$ $0.05)$, with the same-pattern but smaller self-advantage $\left(M_{\text {self }}=953 \mathrm{~ms} ; M_{\text {friend }}=1006 \mathrm{~ms}\right.$; $\left.M_{\text {other }}=993 \mathrm{~ms}\right)$.

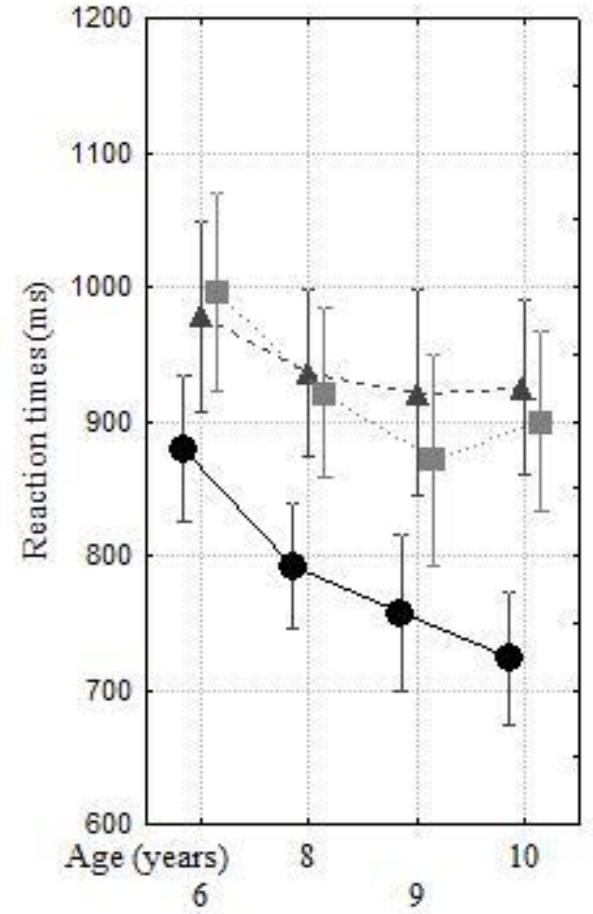

Matched trials

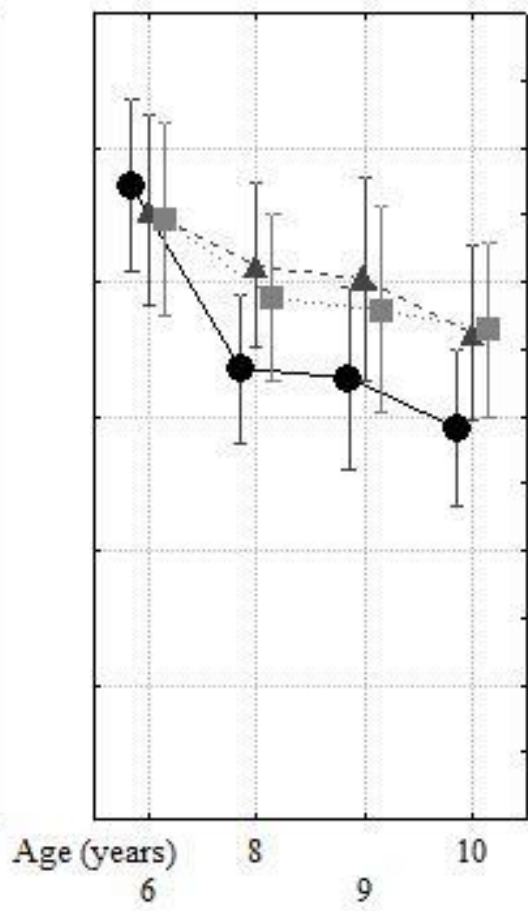

Non-matched trials
Self Friend Other

Figure 2: RTs as a function of character (self, friend, other) for matched and non-matched trials in the "6 years", "8 years", "9 years" and "10 years" mean age groups (Grade 1, Grade 3, Grade 4 and Grade 5 groups, respectively) (bars represent Standard Errors of Means)

\section{Accuracy Rates}

A 3 (character: self, friend, other) x 2 (matching condition: matched trials, nonmatched trials) x 4 (mean age: $6,8,9,10$ ) repeated-measures ANOVA was conducted. This analysis revealed a main effect of matching condition $\left(F(1,128)=17.31, p<.001, \eta_{\mathrm{p}}^{2}=\right.$ $0.12)$, with more accurate responses for matched trials than for non-matched trials $\left(M_{\text {matched }}=\right.$ 
$\left.74 \%, M_{n o n-m a t c h e d}=69 \%\right)$, a main effect of age $\left(F(3,128)=7.04 p<.001, \eta_{\mathrm{p}}{ }^{2}=0.05\right)$ with participants becoming overall more accurate with age $\left(M_{6 \text { years }}=68 \%, M_{8 \text { years }}=66 \%, M_{9 \text { years }}\right.$ $\left.=75 \%, M_{10 \text { years }}=77 \%\right)$, and a main effect of character $\left(F(2,256)=6.22, p<.01, \eta_{\mathrm{p}}^{2}=\right.$ 0.02 ) with more accurate responses for "self" trials $\left(M_{\text {friend }}=74 \%\right)$ than for "other" and "friend" trials $\left(M_{\text {other }}=71 \% ; M_{\text {friend }}=69 \%\right)$. Post-hoc Tukey comparisons showed significantly higher accuracy rates for "self" trials relative to "other" trials $(p<.001)$, a trend for an advantage for "self" trials relative to "friend" trials $(p<.10)$, but no significant difference between "other" and "friend" trials $(p>.05)$. A significant Character x Matching condition interaction was obtained $\left(F(2,256)=15.39, p<.001, \eta_{\mathrm{p}}^{2}=0.05\right)$, with a larger effect of character for matched than for non-matched trials, pointing out an SPE on accuracy rates (see Figure 3). No other significant interactions were found. Importantly, the Character $x$ Matching condition $\mathrm{x}$ Age was not significant $(F(6,256)=1.04, p>.05, n s)$. The analyses for the matched and the non-matched trials were then conducted separately. A significant effect of Character was obtained only for the matched trials $\left(F(2,256)=17.74, p<.001, \eta_{\mathrm{p}}^{2}=0.06\right)$, with a "self"-association advantage $\left(M_{\text {self }}=80 \%\right)$ over "friend"- and "other"- associations $\left(M_{\text {friend }}=69 \% ; M_{\text {other }}=73 \%\right)$. In contrast, there was no significant effect of Character for the non-matched trials $(F(2,256)=2.88, p>.05, n s)$. 


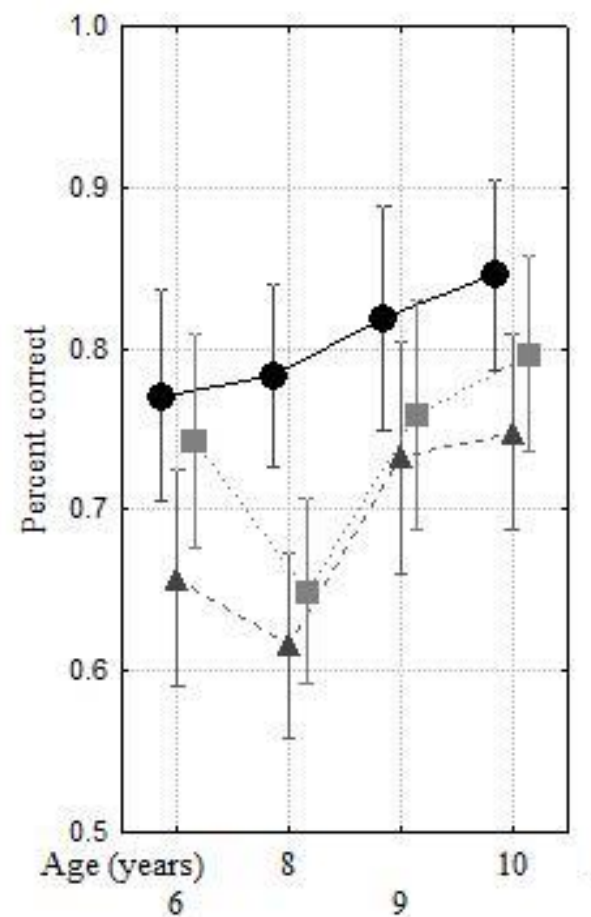

Matched trials

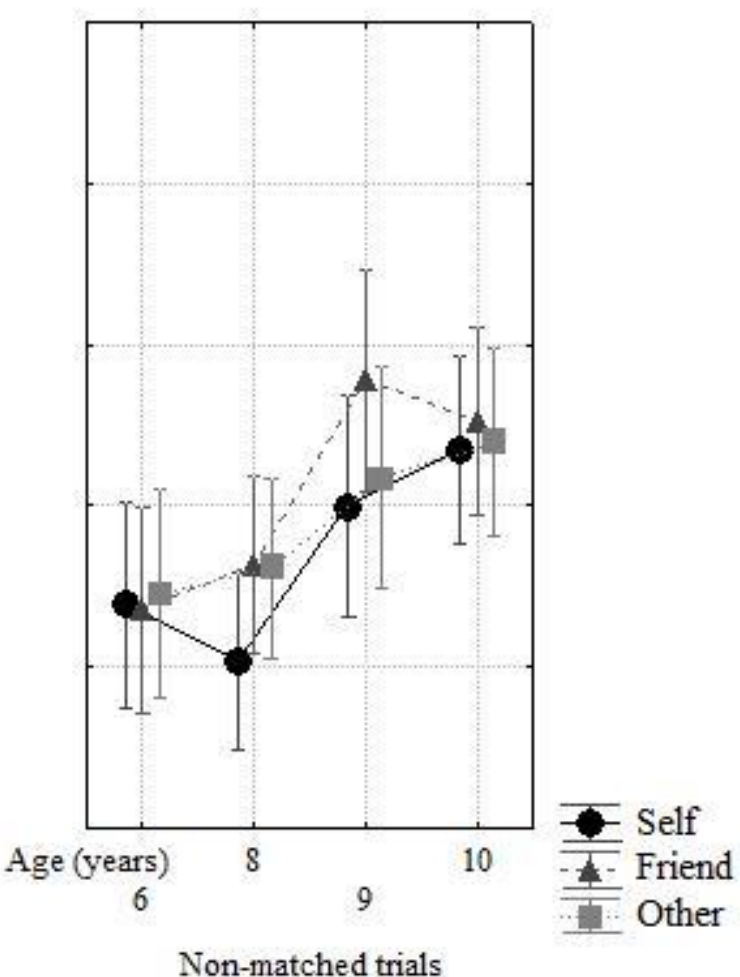

Non-matched trials

Figure 3: Accuracy as a function of character (self, friend, other) for matched and nonmatched trials in the "6 years", "8 years", "9 years" and "10 years" mean age groups (Grade 1, Grade 3, Grade 4 and Grade 5 groups, respectively) (bars represent Standard Errors of Means)

\section{D primes}

Following Sui and colleagues $(2012,2015)$, in addition to RTs and accuracy rates, performance was also analyzed using a Signal Detection Theory approach. For each participant, d prime was calculated as a measure of sensitivity for discriminating between matched and non-matched trials for the different association categories (see Table 1). This measure was derived using the Green and Swets (1966) formula: d' $=z($ Hit $)-z(F A)$. A 3 (character: self, friend, other) x 4 (mean age: 6, 8, 9, 10) repeated-measures ANOVA was then conducted. This analysis revealed a main effect of age $\left(F(3,128)=6.70, p<.001, \eta_{\mathrm{p}}^{2}=\right.$ $0.05)$-with an overall increasing $d$ ' with age $\left(M_{6 \text { years }}=1.158, M_{8 \text { years }}=0.986, M_{9}\right.$ years $=$ $\left.1.602, M_{10 \text { years }}=1.699\right)$, and a main effect of character $\left(F(2,256)=7.97, p<.001, \eta_{\mathrm{p}}^{2}=\right.$ $0.03)$, with better sensitivity for discriminating for "self" trials $\left(M_{\text {self }}=1.524\right)$ than for "other" and "friend" trials $\left(M_{\text {other }}=1.340 ; M_{\text {friend }}=1.219\right)$. Post-hoc Tukey comparisons revealed that 
$d$ ' for "self" trials were significantly higher than $d$ ' for "friend" $(p<.001)$ and for "other" $(p<$ $.05)$ trials, whereas $d$ ' for "other" and "friend" trials were not significantly different $(p>.05)$. No significant Age $\mathrm{x}$ Character interaction was observed $(p>.05)$, indicating that this better sensitivity for "self" trials remained stable with age.

\section{Discussion}

The current research was designed to test whether an SPE could be obtained in children with an age-appropriate task, and if so, whether such an effect would remain stable or not with age. Our results showed a significant SPE in children, pointing out a robust perceptual advantage for self-related information already present at the age of 6 years, as previously reported in adults by Sui and colleagues (2012). A second outcome of our results is that the SPE did not vary as a function of age, suggesting that this perceptual self-advantage results from a property of the self that remains stable throughout development. Since between the ages of 6 and 10 years the self-concept conversely develops into a more and more elaborate and well-developed construct (e.g. Rochat, 2009), the SPE is not dependent on integration of stimuli within extant self knowledge. To sum up, the perceptual self-advantage we captured here (SPE) and to some extent the incidental SRE both result exclusively from low-level and automatic responses to the self (cf. in adult, Alexopoulos et al., 2012; Turk et al., 2008, 2013) and stems from an age-invariant property of the self. In contrast, the SRE may rather be a mixed phenomenon which comprises both high-level influences sensitive to the development of the self-concept (e.g., in adult, Andersen et al., 1998; Keenan et al., 1992; Klein et al., 1994), required for the evaluative SRE, and low-level and automatic influences (Cunningham et al., 2014; Turk et al., 2008, 2013) similar to those eliciting both the SPE and the incidental SRE.

This distinction between an age-invariant property of being automatically receptive to mere self-cues and an age-dependent development of the self-concept echoes two functionally 
distinct levels of the self initially proposed by James (1890). The first level is the "I", the implicit, minimal and descriptive level, at which the self is merely a subject of experience. The second level is the "me", the explicit, reflexive and agentic level, at which the self has become a conscious object of knowledge for oneself, allowing the self to become the subject of one's own attention (Legrain, Cleeremans, \& Destrebecqz, 2011). Similar differentiations have also been made in many studies between the "subjective" and the "objective" self (Duval \& Wicklund, 1972), the "proto-" and "autobiographical" self (Damasio, 1999), the "minimal" and the "narrative" self (Gallagher, 2000), the "core" and the "experiential" self (Northoff, Heinzel, De Greck, Bermpohl, Dobrowolny, \& Panksepp, 2006), as well as between "ecologic" and "conceptual" self-consciousness (Rochat, 2003). Following this distinction, we propose that the SPE, and to some extent the incidental SRE, involve the mere implicit, minimal and descriptive "I", related to a stable and automatic sensitivity to self-cues, but do not require the explicit, reflexive and agentic "me", related to a more and more mature and well-developed self-concept. Between the two poles of the "I-me" continuum, some adult studies showed that a form of low-level, current self-recognition may yet be required in both SRE and SPE. For instance, conscious recognition of self was required in the incidental SRE (Kim, Jeon, Banquer, \& Rothschild, 2018, for priming studies), and the SPE occurs only when the matching was made with current self-representation, but not with representations of the self in the future (Golubickis, Falben, Sahraie, Visokomogilski, Cunningham, Sui, \& Macrae, 2017).

In the present study, for the first time, we successfully adapted for children as young as 6 years old a paradigm extensively used in adults to investigate mere automatic responses to the self. We could demonstrate clear self-prioritization effects in children. Following previous studies using both evaluative and incidental SRE paradigms (Cunningham et al., 2013, 2014; Ross et al., 2019), the present task provides a measure of the self-advantage which is precise, by quantifying a specific self-related increase of their response speed, "on- 
line", by capturing this self-advantage in real time, and which avoids familiarity effects elicited by own faces. Further research is required with 7 year-old as well as with younger children (6 years of age and less) in order to determine the age at which such perceptual selfbiases emerge. For a better understanding of the children SRE, coupling an SRE assessment with our matching task in children from a broad age-span range (3-10 year-old) would examine how the burgeoning high-level influences stemming from the development of the self-concept may gradually add-up to the stable, minimal and automatic responses to selfcues, and consequently increase the size of the evaluative SRE (Halpin et al., 1984; Ray et al., 2009) while the SPE should be age-invariant.

Acknowledgments: Many thanks to Kelley Kaye for her precious remarks on this paper and to the following students who helped collecting the data: Yushan Dai, Aurélie Daul, Florian Fellman, Estelle Guyot, Lisa Lhospital and Laura Vuidart. 


\section{References}

Alexopoulos, T., Muller, D., Ric, F., \& Marendaz, C. (2012). I, me, mine: Automatic attentional capture by self-related stimuli. European Journal of Social Psychology, 42(6), 770-779. doi:10.1002/ejsp.1882

Andersen, S. M., Glassman, N. S., \& Gold, D. A. (1998). Mental representations of the self, significant others, and nonsignificant others: Structure and processing of private and public aspects. Journal of Personality and Social Psychology, 75(4), 845-861. doi:10.1037/0022-3514.75.4.845

Bargh, J. A. (1982). Attention and automaticity in the processing of self-relevant information. Journal of Personality and Social Psychology, 43, 425-436. doi:10.1037/ 00223514.43.3.425

Beggan, J. K. (1992). On the social nature of nonsocial perception: The mere ownership effect. Journal of Personality and Social Psychology, 62(2), 229-237.

Craik, F. I., \& Lockhart, R. S. (1972). Levels of processing: A framework for memory research. Journal of Verbal Learning and Verbal Behavior, 11(6), 671-684. doi:10.1016/S0022-5371(72)80001-X

Cunningham, S. J., Brebner, J. L., Quinn, F., \& Turk, D. J. (2014). The self-reference effect on memory in early childhood. Child Development, 85(2), 808-823. doi:10.1111/cdev.12144

Cunningham, S. J., Scott, L., Hutchison, J., Ross, J., \& Martin, D. (2018). Applying selfprocessing biases in education: Improving learning through ownership. Journal of Applied Research in Memory and Cognition. doi:10.1016/j.jarmac.2018.04.004

Cunningham, S. J., \& Turk, D. J. (2017). A review of self-processing biases in cognition. The Quarterly Journal of Experimental Psychology, 70(6), 987-995. doi:10.1080/17470218.2016.1276609 
Cunningham S, Vergunst F, Macrae C, Turk D. (2013). Exploring early self-referential memory effects through ownership. British Journal of Developmental Psychology, 31(3), 289-301. doi:10.1111/bjdp.12005

Damasio, A. R. (1999). The feeling of what happens: Body and emotion in the making of consciousness. New York: Harcourt Brace.

Duval, T. S., \& Wicklund, R. A. (1972). A theory of objective self-awareness. New York: Academic Press.

Frings, C., \& Wentura, D. (2014). Self-priorization processes in action and perception. Journal of Experimental Psychology: Human Perception and Performance, 40(5), 1737-1740. doi:10.1037/a0037376

Fuentes, L. J., Sui, J., Estévez, A. F., \& Humphreys, G. W. (2016). The differential outcomes procedure can overcome self-bias in perceptual matching. Psychonomic Bulletin and Review, 23(2), 451-458. doi:10.3758/s13423-015-0895-3

Gallagher, S. (2000). Philosophical conceptions of the self: Implications for cognitive science. Trends in Cognitive Sciences, 4, 14-21. doi: 10.1016/S1364-6613(99)01417-5

Golubickis, M., Falben, J. K., Sahraie, A., Visokomogilski, A., Cunningham, W. A., Sui, J., \& Macrae, C. N. (2017). Self-prioritization and perceptual matching: The effects of temporal construal. Memory and Cognition, 45(7), 1223-1239. doi:10.3758/s13421017-0722-3

Green, D. M., \& Swets, J. A. (1966). Signal detection theory and psychophysics. New York: Wiley.

Halpin, J. A., Puff, C. R., Mason, H. F., \& Marston, S. P. (1984). Self-reference encoding and incidental recall by children. Bulletin of the Psychonomic Society, 22(2), 87-89. doi:10.3758/BF03333770 
Humphreys, G. W., \& Sui, J. (2015). The salient self: Social saliency effects based on selfbias. Journal of Cognitive Psychology, 27(2), 129-140. doi:10.1080/20445911.2014.996156

James, W. (1890). Principles of psychology. New York: Holt, Rinehart and Winston.

Keenan, J. M., Golding, J. M., \& Brown, P. (1992). Factors controlling the advantage of selfreference over other-reference. Social Cognition, 10(1), 79-94. doi:10.1521/soco.1992.10.1.79

Kim, K., Jeon, Y. A., Banquer, A. M., \& Rothschild, D. J. (2018). Conscious awareness of self-relevant information is necessary for an incidental self-memory advantage. Consciousness and Cognition, 65, 228-239. doi:10.1016/j.concog.2018.09.004

Klein, S. B., Loftus, J., \& Schell, T. (1994). Repeated testing: A technique for assessing the roles of elaborative and organizational processing in the representation of social knowledge. Journal of Personality and Social Psychology, 66(5), 830-839. doi:10.1037/0022-3514.66.5.830

Knetsch, J. L. (1989). The endowment effect and evidence of nonreversible indifference curves. American Economic Review, 79(5), 1277-1284.

Legrain, L., Cleeremans, A., \& Destrebecqz, A. (2011). Distinguishing three levels in explicit self-awareness. Consciousness and Cognition, 20(3), 578-585. doi:10.1016/j.concog.2010.10.010

Liu, M., \& Sui, J. (2016). The interaction between social saliency and perceptual saliency. The Quarterly Journal of Experimental Psychology, 69(12), 2419-2430. doi:10.1080/17470218.2015.1120330

Moradi, Z., Sui, J., Hewstone, M., \& Humphreys, G. W. (2015). In-group modulation of perceptual matching. Psychonomic Bulletin and Review, 22(5), 1255-1277. doi:10.3758/s13423-014-0798-8 
Neisser, U. (1988). Five kinds of self-knowledge. Philosophical Psychology, 1, 35-59. doi:10.1080/09515088808572924

Northoff, G., Heinzel, A., De Greck, M., Bermpohl, F., Dobrowolny, H., \& Panksepp, J. (2006). Self-referential processing in our brain —a meta-analysis of imaging studies on the self. Neuroimage, 31(1), 440-457. doi:10.1016/j.neuroimage.2005.12.002

Nuttin Jr, J. M. (1985). Narcissism beyond Gestalt and awareness: The name letter effect. European Journal of Social Psychology, 15(3), 353-361. doi:10.1002/ejsp.2420150309

Pullyblank, J., Bisanz, J., Scott, C., \& Champion, M. A. (1985). Developmental invariance in the effects of functional self-knowledge on memory. Child Development, 1447-1454. doi: $10.2307 / 1130464$

Ray, R. D., Shelton, A. L., Hollon, N. G., Michel, B. D., Frankel, C. B., Gross, J. J., \& Gabrieli, J. D. (2009). Cognitive and neural development of individuated selfrepresentation in children. Child Development, 80(4), 1232-1242. doi:10.1111/j.14678624.2009.01327.x

Rochat, P. (2003). Five levels of self-awareness as they unfold early in life. Consciousness and Cognition, 12(4), 717-731. doi:10.1016/S1053-8100(03)00081-3

Rochat, P. (2009). Others in mind: Social origins of self-consciousness. Cambridge: Cambridge University Press.

Rogers, T. B., Kuiper, N. A., \& Kirker, W. S. (1977). Self-reference and the encoding of personal information. Journal of Personality and Social Psychology, 35(9), 677-688. doi:10.1037/0022-3514.35.9.677

Ross, J., Anderson, J. R., \& Campbell, R. N. (2011). I remember me: Mnemonic selfreference effects in preschool children. Monographs of the Society for Research in Child Development, 76(3), 1-87. 
Ross, J., Hutchison, J., \& Cunningham, S. J. (2019). The Me in memory: The role of the Self in autobiographical memory development. Child Development. doi:10.1111/cdev.13211

Schäfer, S., Wentura, D., \& Frings, C. (2015). Self-prioritization beyond perception. Experimental Psychology, 62(6), 415-425. doi:10.1027/1618-3169/a000307

Schäfer, S., Wentura, D., \& Frings, C. (2017). Distinctiveness effects in self-prioritization. Visual Cognition, 25(1-3), 399-411. doi:10.1080/13506285.2017.1346739

Schäfer, S., Wesslein, A. K., Spence, C., Wentura, D., \& Frings, C. (2016). Self-prioritization in vision, audition, and touch. Experimental Brain Research, 234(8), 2141-2150. doi:10.1007/s00221-016-4616-6

Stein, T., Siebold, A., \& van Zoest, W. (2016). Testing the idea of privileged awareness of self-relevant information. Journal of Experimental Psychology: Human Perception and Performance, 42(3), 303-307. doi:10.1037/xhp0000197

Sui, J., He, X., \& Humphreys, G. W. (2012). Perceptual effects of social salience: Evidence from self-prioritization effects on perceptual matching. Journal of Experimental Psychology: Human Perception and Performance, 38(5), 1105-1117. doi:10.1037/a0029792

Sui, J., \& Humphreys, G. W. (2015a). The integrative self: How self-reference integrates perception and memory. Trends in Cognitive Sciences, 19(12), 719-728. doi:10.1016/j.tics.2015.08.015

Sui, J., \& Humphreys, G. W. (2015b). The interaction between self-bias and reward: Evidence for common and distinct processes. The Quarterly Journal of Experimental Psychology, 68(10), 1-13. doi:10.1080/17470218.2015.1023207

Sui, J., Liu, M., Mevorach, C., \& Humphreys, G. W. (2015). The salient self: The left intraparietal sulcus responds to social as well as perceptual-salience after selfassociation. Cerebral Cortex, 25(4), 1060-1068. doi:10.1093/cercor/bht302 
Sui, J., Ohrling, E., \& Humphreys, G. W. (2016). Negative mood disrupts self-and rewardbiases in perceptual matching. The Quarterly Journal of Experimental Psychology, 69(7), 1438-1448. doi:10.1080/17470218.2015.1122069

Sui, J., Sun, Y., Peng, K., \& Humphreys, G. W. (2014). The automatic and the expected self: Separating self- and familiarity biases effects by manipulating stimulus probability. Attention, Perception and Psychophysics, 76(4), 1176-1184. doi:10.3758/s13414-014$0631-5$

Sui, J., Yankouskaya, A., \& Humphreys, G. W. (2015). Super-capacity me! Super-capacity and violations of race independence for self- but not for reward-associated stimuli. Journal of Experimental Psychology: Human Perception and Performance, 41(2), 441-452. doi:10.1037/a0038288

Sui, J., \& Zhu, Y. (2005). Five-year-olds can show the self-reference advantage. International Journal of Behavioral Development, 29, 382-387. doi:10.1080/01650250500172673

Sun, Y., Fuentes, L. J., Humphreys, G. W., \& Sui, J. (2016). Try to see it my way: Embodied perspective enhances self and friend-biases in perceptual matching. Cognition, 153, 108-117. doi:10.1016/j.cognition.2016.04.015

Symons, C. S., \& Johnson, B. T. (1997). The self-reference effect in memory: A metaanalysis. Psychological Bulletin, 121(3), 371-394. doi:10.1037/0033-2909.121.3.371

Turk, D., Bos, M., Collard, P., Gillespie-Smith, K., Conway, M., \& Cunningham, S. (2013). Divided attention selectively impairs memory for self-relevant information. Memory and Cognition, 41(4), 503-510. doi:10.3758/s13421-012-0279-0

Turk, D. J., Cunningham, S. J., \& Macrae, C. N. (2008). Self-memory biases in explicit and incidental encoding of trait adjectives. Consciousness and Cognition, 17(3), 10401045. doi:10.1016/j.concog.2008.02.004

Turk, D. J., Gillespie-Smith, K., Krigolson, O. E., Havard, C., Conway, M. A., \& Cunningham, S. J. (2015). Selfish learning: The impact of self-referential encoding on 
children's literacy attainment. Learning and Instruction, 40, 54-60. doi:10.1016/j.learninstruc.2015.08.001

van den Bos, M., Cunningham, S. J., Conway, M. A., \& Turk, D. J. (2010). Mine to remember: The impact of ownership on recollective experience. The Quarterly Journal of Experimental Psychology, 63(6), 1065-1071. doi:10.1080/17470211003770938

Wang, H., Humphreys, G., \& Sui, J. (2016). Expanding and retracting from the self: Gains and costs in switching self-associations. Journal of Experimental Psychology: Human Perception and Performance, 42(2), 247-256. doi:10.1037/xhp0000125 